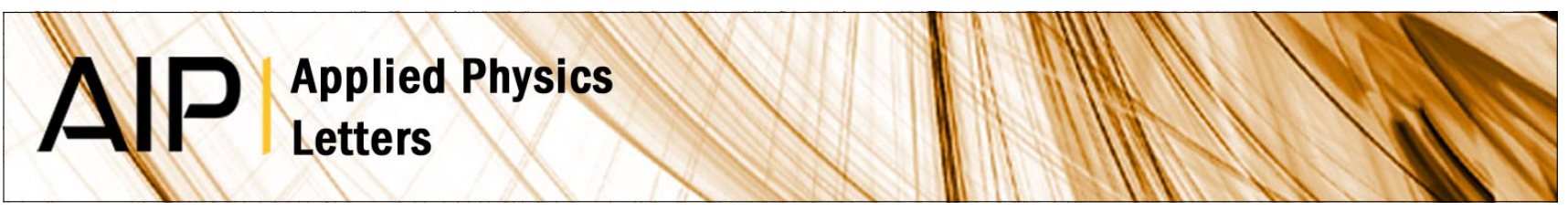

\title{
On the mechanism for plasma hydrogenation of graphene
}

\author{
J. D. Jones, W. D. Hoffmann, A. V. Jesseph, C. J. Morris, G. F. Verbeck et al.
}

Citation: Appl. Phys. Lett. 97, 233104 (2010); doi: 10.1063/1.3524517

View online: http://dx.doi.org/10.1063/1.3524517

View Table of Contents: http://apl.aip.org/resource/1/APPLAB/v97/i23

Published by the American Institute of Physics.

\section{Related Articles}

Strength of hydrogen bonds of water depends on local environment J. Chem. Phys. 136, 144305 (2012)

Modeling of an ionic liquid electrospray using molecular dynamics with constraints J. Chem. Phys. 136, 124507 (2012)

Epitaxial oxide bilayer on $\mathrm{Pt}(001)$ nanofacets

J. Chem. Phys. 136, 044704 (2012)

Comment on "The electromagnetic property of chemically reduced graphene oxide and its application as microwave absorbing material” [Appl. Phys. Lett. 98, 072906 (2011)]

Appl. Phys. Lett. 100, 046101 (2012)

Ignition of an exothermal reaction by collision between $\mathrm{Al}$ and $\mathrm{Ni}$ crystals

J. Appl. Phys. 110, 103505 (2011)

\section{Additional information on Appl. Phys. Lett.}

Journal Homepage: http://apl.aip.org/

Journal Information: http://apl.aip.org/about/about_the_journal

Top downloads: http://apl.aip.org/features/most_downloaded

Information for Authors: http://apl.aip.org/authors

\section{ADVERTISEMENT}




\title{
On the mechanism for plasma hydrogenation of graphene
}

\author{
J. D. Jones, ${ }^{1}$ W. D. Hoffmann, ${ }^{2}$ A. V. Jesseph, ${ }^{2}$ C. J. Morris, ${ }^{1}$ G. F. Verbeck, ${ }^{2}$ and \\ J. M. Perez ${ }^{1, \text { a) }}$ \\ ${ }^{1}$ Department of Physics, University of North Texas, Denton, Texas 76203, USA \\ ${ }^{2}$ Department of Chemistry, University of North Texas, Denton, Texas 76203, USA
}

(Received 20 September 2010; accepted 8 November 2010; published online 6 December 2010)

\begin{abstract}
We report that hydrogenation of mono-, bi-, and trilayer graphene samples via exposure to $\mathrm{H}_{2}$ plasma occurs as a result of electron irradiation of $\mathrm{H}_{2} \mathrm{O}$ adsorbates on the samples, rather than $\mathrm{H}$ species in the plasma as reported by [Elias et al., Science 323, 610 (2009)]. We propose that the hydrogenation mechanism is electron-impact fragmentation of $\mathrm{H}_{2} \mathrm{O}$ adsorbates into $\mathrm{H}^{+}$ions. At incident electron energies $>60 \mathrm{eV}$, we observe hydrogenation that is significantly more stable at temperatures $>200{ }^{\circ} \mathrm{C}$ than previously reported. (C) 2010 American Institute of Physics.
\end{abstract}

[doi:10.1063/1.3524517]

Monolayer graphene (MLG), a single layer of $s p^{2}$-bonded $\mathrm{C}$ atoms, has recently attracted considerable interest due to its unique structural and electronic properties. ${ }^{1}$ Of particular interest has been the hydrogenation of MLG (Refs. 2 and 3) and multilayer graphene ${ }^{4}$ by exposure to $\mathrm{H}_{2}$ plasma. Fully hydrogenated MLG, graphene, is $s p^{3}$-bonded and predicted to have a band gap of $3.5 \mathrm{eV}^{5}$ However, hydrogenated MLG has been reported to significantly dehydrogenate at temperatures $T=100{ }^{\circ} \mathrm{C}$ and almost completely revert back to its nonhydrogenated form at $T=200{ }^{\circ} \mathrm{C},{ }^{3}$ limiting its applications. It is thought that plasma hydrogenation is due to $\mathrm{H}$ ions and radicals in the plasma that react with the graphene surface. ${ }^{2,4}$ It is important to understand the mechanisms for plasma modification of graphene in order to fully utilize this phenomenon. In this paper, we study $\mathrm{H}_{2}$ plasma hydrogenation of MLG, bilayer graphene (BLG), and trilayer graphene (TLG) while varying sample preparation and bias.

Our samples were made by mechanical exfoliation of highly oriented pyrolitic graphite (HOPG) onto a $300 \mathrm{~nm}$ thick $\mathrm{SiO}_{2}$ layer grown on a $\mathrm{Si}$ wafer. ${ }^{1}$ The exfoliation was carried out in air at room temperature (RT) and relative humidity of $50 \%$, producing samples that have $\mathrm{H}_{2} \mathrm{O}$ adsorbed on the top and bottom from contact with the air and $\mathrm{SiO}_{2}$. Adsorbates such as $\mathrm{H}_{2} \mathrm{O}$ can be removed from MLG by annealing at $T=150{ }^{\circ} \mathrm{C}^{6}$ We annealed samples at $T \leq 400{ }^{\circ} \mathrm{C}$ and $400{ }^{\circ} \mathrm{C}<T<645{ }^{\circ} \mathrm{C}$ in vacuum at pressures of $10^{-6}$ and $10^{-10}$ Torr, respectively. Test samples annealed under such conditions show no damage as inferred from Raman spectroscopy. We did not anneal at $T>645{ }^{\circ} \mathrm{C}$ to avoid desorption of $\mathrm{SiO}_{2}$ from the substrate. We compared the effects of plasma exposure on MLG, BLG, and TLG regions that were on the same graphite flake to achieve similar exposure conditions. Our plasma system consists of a $50 \mathrm{~W}, 19-21$ $\mathrm{MHz}$ rf source that is capacitively coupled to a quartz tube. More detailed descriptions of our sample preparation and plasma system are given in the supplementary materials. ${ }^{7}$

Graphite is characterized by a set of Raman peaks: a $G$ peak at $1580 \mathrm{~cm}^{-1}$ due to the in-plane vibrational $E_{2 G}$ mode, and a $2 D$ peak at about $2700 \mathrm{~cm}^{-1}$ due to two phonon intervalley scattering. ${ }^{2}$ Hydrogenated graphene shows an addi-

${ }^{a)}$ Electronic mail: jperez@unt.edu. tional sharp $D$ peak at about $1340 \mathrm{~cm}^{-1}$ that is activated by defects. ${ }^{2-4}$ For hydrogenated graphene, the integrated intensity of the $D$ peak, $I_{D}$, saturates at a value two to three times greater than that of the $G$ peak, $I_{G}{ }^{2-4}$ The disappearance of the $D$ peak after annealing at $T=200{ }^{\circ} \mathrm{C}$ is taken as evidence for dehydrogenation ${ }^{3}$ since HOPG dehydrogenates at these temperatures. Figure 1(a) shows micro-Raman data, taken at an excitation wavelength of $532 \mathrm{~nm}$, for a pristine sample showing no $D$ peak and a $2 D$ peak with a full-width-at-half maximum of $30 \mathrm{~cm}^{-1}$, indicating MLG. Figure 1(b) shows data for the same sample shown in Fig. 1(a) after exposure to $\mathrm{H}_{2}$ plasma at 50 mTorr for $10 \mathrm{~s}$ with the sample electrically floating. We observe a sharp $D$ peak with $I_{D} / I_{G}=3.2$, consistent with hydrogenated graphene, and $D^{\prime}$ and $\left(D+D^{\prime}\right)$ peaks that have also been attributed to hydrogenation. ${ }^{2,4}$ The dotted

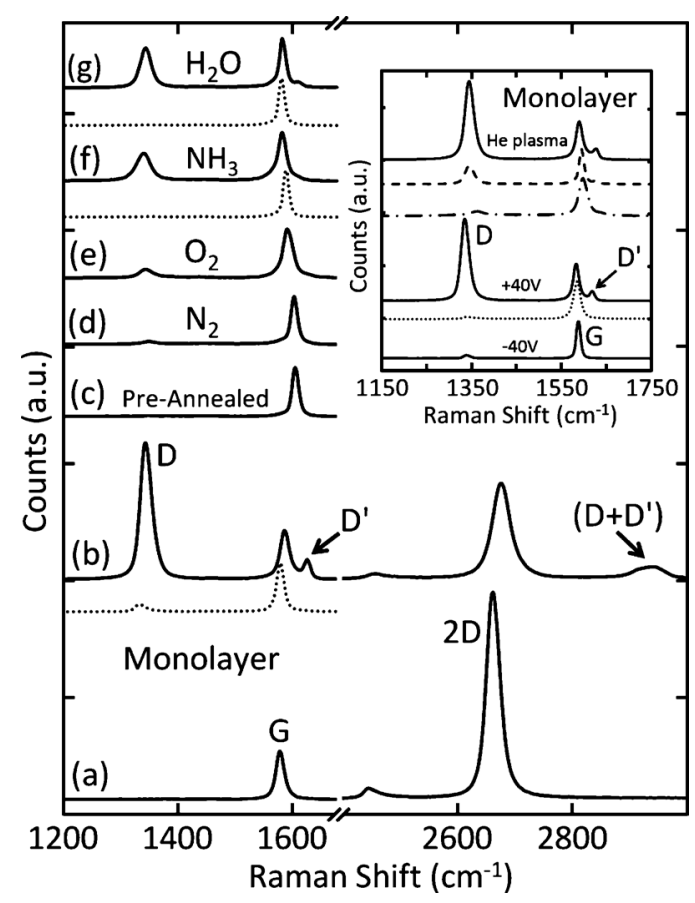

FIG. 1. Monolayer samples. (a) Pristine. (b) Exposed to $\mathrm{H}_{2}$ plasma. (c) Preannealed then exposed to $\mathrm{H}_{2}$ plasma. (d)-(f) Preannealed then exposed to $\mathrm{N}_{2}, \mathrm{O}_{2}, \mathrm{H}_{2} \mathrm{O}$, and $\mathrm{NH}_{3}$ gasses, respectively, then to $\mathrm{H}_{2}$ plasma. Inset shows spectra of samples exposed to $\mathrm{H}_{2}$ plasma at biases of -40 and $40 \mathrm{~V}$ and dosages of 1.1 and $6.5 \mathrm{mC} / \mathrm{cm}^{2}$, respectively, and exposed to He plasma. 


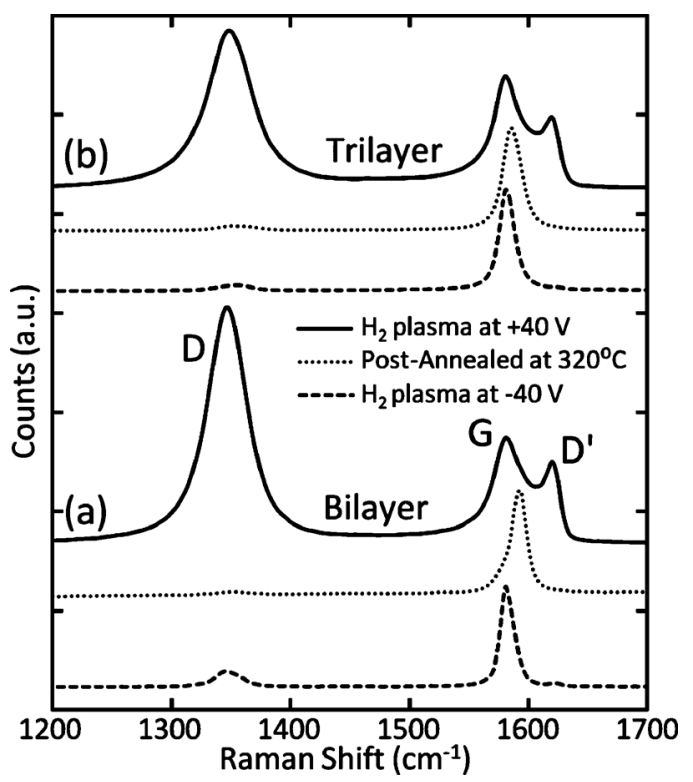

FIG. 2. (a) and (b) Bi- and trilayer samples, respectively. Exposure dosages of electrons at $40 \mathrm{~V}$ and ions at $-40 \mathrm{~V}$ were 6.5 and $1.1 \mathrm{mC} / \mathrm{cm}^{2}$, respectively.

curve in Fig. 1(b) shows data after we have postannealed a hydrogenated sample having $I_{D} / I_{G}=3$ at $220{ }^{\circ} \mathrm{C}$ for $1 \mathrm{~h}$. The $D$ peak nearly disappears, as in previous reports. ${ }^{3}$ Figure $1(\mathrm{c})$ shows data for a pristine MLG sample that is preannealed within the plasma chamber at $400{ }^{\circ} \mathrm{C}$ for $1 \mathrm{~h}$ to remove adsorbates, and then exposed to the same $\mathrm{H}_{2}$ plasma conditions as in Fig. 1(b). We observe a shift in the $G$ peak of roughly $20 \mathrm{~cm}^{-1}$ from the pristine to preannealed sample. This effect has been previously reported and attributed to hole-doping from exposure to $\mathrm{O}_{2}$ in the atmosphere. ${ }^{8} \mathrm{~A} D$ peak is not observed, indicating that adsorbates rather than $\mathrm{H}$ species in the plasma are responsible for the $D$ peak. To identify the adsorbates, we preannealed MLG samples at $400{ }^{\circ} \mathrm{C}$ for $1 \mathrm{~h}$, exposed them in situ to $\mathrm{N}_{2}, \mathrm{O}_{2}, \mathrm{H}_{2} \mathrm{O}$, and $\mathrm{NH}_{3}$ gases at RT and 20 Torr for $1 \mathrm{~h}$, and then exposed them to the same $\mathrm{H}_{2}$ plasma conditions as in Fig. 1(b) with the sample floating. As shown in Figs. 1(d)-1(g), samples exposed to $\mathrm{H}_{2} \mathrm{O}$ and $\mathrm{NH}_{3}$ showed significantly higher $I_{D} / I_{G}$ $=1.2$ and 0.8 , respectively, than those exposed to $\mathrm{N}_{2}$ and $\mathrm{O}_{2}$ that showed $I_{D} / I_{G}=0.1$ and 0.2 , respectively. The dotted curves in Figs. 1(f) and 1(g) refer to Raman spectra after the gas dosing, but before the $\mathrm{H}_{2}$ plasma exposure. Since $\mathrm{H}_{2} \mathrm{O}$ and $\mathrm{NH}_{3}$ adsorb on MLG (Ref. 6) and contain $\mathrm{H}$, these results lead us to hypothesize that the $D$ peak, due to hydrogenation, is caused by fragmentation of $\mathrm{H}$ species from these adsorbates. We note that pristine samples are exposed to adsorbates on both sides, whereas preannealed samples are only exposed on the top surface due to the lack of diffusion under the layer. The smaller values of $I_{D} / I_{G}$ for samples exposed to $\mathrm{H}_{2} \mathrm{O}$ and $\mathrm{NH}_{3}$ versus those for pristine samples in Fig. 1(b) are attributed to exposed samples having adsorbates on only the top. We conclude that the $D$ peak in Fig. 1(b) is primarily due to $\mathrm{H}_{2} \mathrm{O}$ adsorbates from the air and $\mathrm{SiO}_{2}$.

To study the effects of electron and ion irradiation on the formation of the $D$ peak, we biased samples at voltages $V$ relative to the chamber during plasma exposure. Since electrons typically have energies of about $2 \mathrm{eV}$, a bias of $V$ results in incident electron energies of $V \pm 2 \mathrm{eV}$. By measuring the current density between the substrate and chamber,

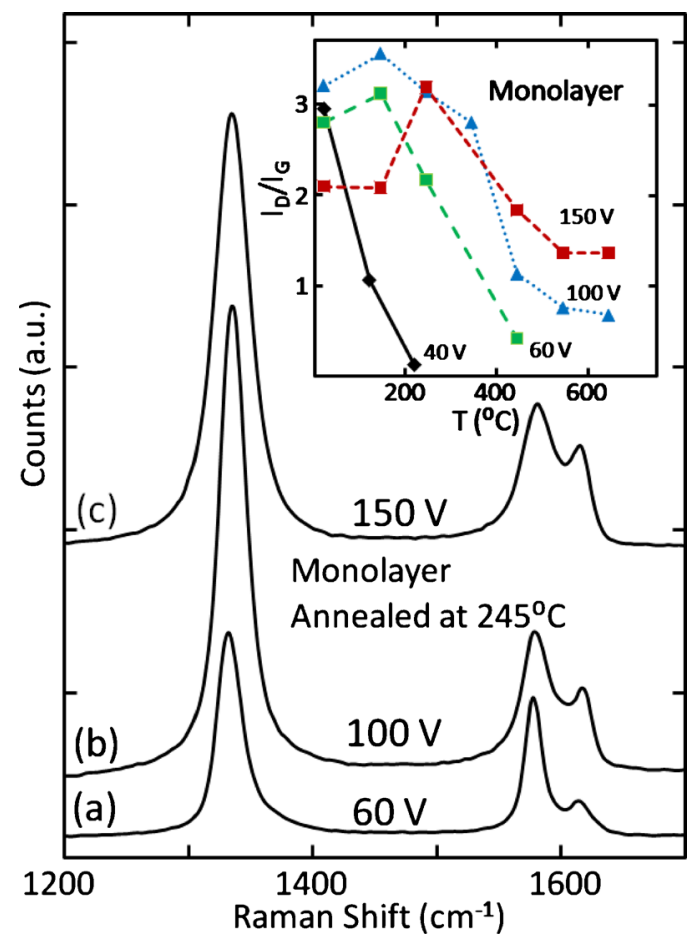

FIG. 3. (Color online) (a)-(c) Monolayer samples exposed to $\mathrm{H}_{2}$ plasma at biases of 60,100 , and $150 \mathrm{~V}$ and dosages of $11.9,15.7$, and $23.2 \mathrm{mC} / \mathrm{cm}^{2}$, respectively, and then postannealed at $245^{\circ} \mathrm{C}$. Inset shows monolayer $I_{D} / I_{G}$ vs annealing temperature $T$, for $40,60,100$, and $150 \mathrm{~V}$ biases at dosages of $6.5,11.9,15.7$, and $23.2 \mathrm{mC} / \mathrm{cm}^{2}$, respectively.

the electron and ion dosages on the substrate are determined. If we assume a uniform current density on the substrate, this dosage is the same as that on the graphene sample. The inset in Fig. 1 shows data for a MLG sample exposed to $\mathrm{H}_{2}$ plasma at 75 mTorr for $10 \mathrm{~s}$ with a sample bias of $-40 \mathrm{~V}$, which repels electrons and attracts positive $\mathrm{H}$ ions from the plasma. Observed is a small $D$ peak with $I_{D} / I_{G}=0.1$. However, under the same plasma conditions and a bias of $40 \mathrm{~V}$, which attracts electrons and repels positive ions, we observe a $D$ peak with $I_{D} / I_{G}=2.8$. Annealing the sample at $220^{\circ} \mathrm{C}$ results in a significant decrease of the $D$ peak to $I_{D} / I_{G}=0.1$, as shown by the dotted curve in the inset. Similar results were observed for BLG and TLG samples, as shown in Fig. 2. Thus we conclude that electron irradiation of $\mathrm{H}_{2} \mathrm{O}$ adsorbates is required for the formation of the $D$ peak. This conclusion is supported by the top curve in the inset in Fig. 1 that shows data for MLG exposed to He plasma, which contains electrons but no $\mathrm{H}$ species, at 75 mTorr for $60 \mathrm{~s}$ with the sample floating. A $D$ peak is still observed with $I_{D} / I_{G}$ $=2.5$, comparable to the $D$ peak in Fig. 1(b) after $\mathrm{H}_{2}$ plasma exposure. As shown by the dashed and dot-dashed curves in the inset, $I_{D} / I_{G}$ decreases to 0.9 and 0.2 after annealing at $T=350$ and $590{ }^{\circ} \mathrm{C}$, respectively.

Assuming that the $D$ peak is due to hydrogenation, we propose that the mechanism is electron-impact fragmentation of $\mathrm{H}_{2} \mathrm{O}$ adsorbates. The cross-section $\sigma$ for fragmentation of $\mathrm{H}_{2} \mathrm{O}$ into $\mathrm{H}^{+}$ions varies from about 1 to $3 \times 10^{-17} \mathrm{~cm}^{2}$ for electron energies from 30 to $1000 \mathrm{eV}$, with a broad maximum at about $100 \mathrm{eV}^{9}$. The probability for fragmentation of an adsorbate is $P=\left(1-e^{-N \sigma}\right)$, where $N$ is the number of incident electrons per $\mathrm{cm}^{2}$. For a dosage of $6.5 \mathrm{mC} / \mathrm{cm}^{2}$ we have $N=4.1 \times 10^{16} / \mathrm{cm}^{2}$. Using $N=4.1 \times 10^{16} / \mathrm{cm}^{2}$ and $\sigma=1-3$ $\times 10^{-17} \mathrm{~cm}^{2}$, we have $P=0.34-0.71$. The cross-section $\sigma$ 


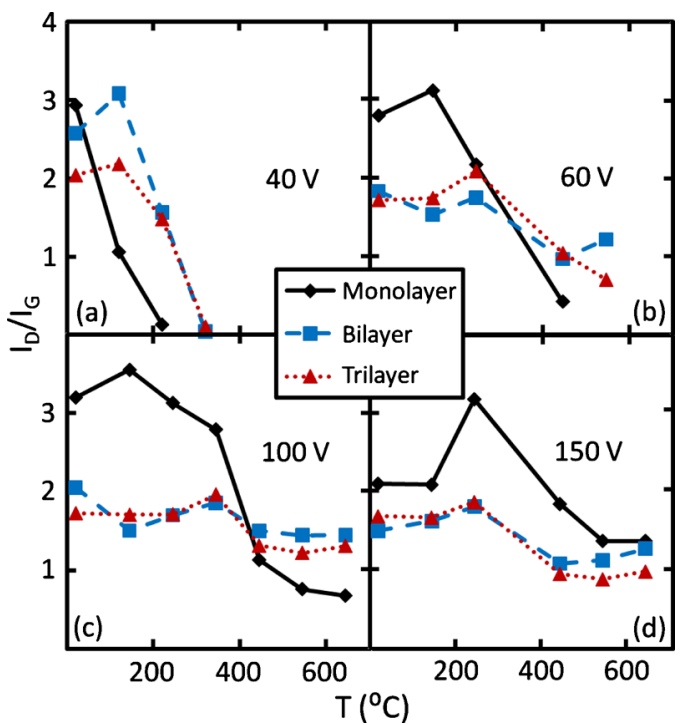

FIG. 4. (Color online) (a)-(d) Mono-, bi-, and trilayer $I_{D} / I_{G}$ vs annealing temperature $T$, for $40,60,100$, and $150 \mathrm{~V}$ biases at dosages of 6.5, 11.9, 15.7 , and $23.2 \mathrm{mC} / \mathrm{cm}^{2}$, respectively.

for fragmentation of $\mathrm{H}_{2} \mathrm{O}$ into $\mathrm{H}^{-}$ions and $\mathrm{H}$ radicals is about one-fifth and one-tenth of that into $\mathrm{H}^{+}$ions, respectively. ${ }^{9}$ Thus we propose that hydrogenation is mainly due to $\mathrm{H}^{+}$ions. Most of the ejected $\mathrm{H}^{+}$ions have energies of $0-5 \mathrm{eV}$ for electron energies of $35-400 \mathrm{eV}^{10}$

Figures 3(a)-3(c) show data for pristine MLG samples exposed to $\mathrm{H}_{2}$ plasma at 75 mTorr for $10 \mathrm{~s}$ and biases of 60 , 100 , and $150 \mathrm{~V}$, respectively, and then postannealed at $T$ $=245{ }^{\circ} \mathrm{C}$ for $1 \mathrm{~h}$. Biases greater than $150 \mathrm{~V}$ were not used because they resulted in arcing. In Figs. 3(a)-3(c), the resulting current densities were $1.2,1.6$, and $2.3 \mathrm{~mA} / \mathrm{cm}^{2}$, respectively. These combinations of energies and current densities are about two orders of magnitude lower than those reported to cause damage in graphene. ${ }^{11}$ Observed in Figs. 3(a)-3(c) are $D$ peaks with $I_{D} / I_{G}=2.2,3.1$, and 3.2, respectively. These values are significantly greater than those previously reported; ${ }^{3}$ these authors found that $I_{D} / I_{G}$ nearly disappeared after annealing at $T=200{ }^{\circ} \mathrm{C}$. The inset in Fig. 3 shows $I_{D} / I_{G}$ as a function of $T$ for MLG samples biased at 40, 60, 100, and $150 \mathrm{~V}$. For samples biased at 100 and $150 \mathrm{~V}, I_{D} / I_{G}$ is about 2 after annealing at $T=400{ }^{\circ} \mathrm{C}$. Figures $4(\mathrm{a})-4(\mathrm{~d})$ show $I_{D} / I_{G}$ as a function of $T$ for MLG, BLG, and TLG samples exposed under the same plasma conditions as Fig. 3 and biases of 40-150 V. For Figs. 4(a)-4(d), each set of curves at a given bias was collected from the same flake. For MLG, BLG, and TLG, the temperature stability of the $D$ peak is observed to be greater at higher biases. We attribute the greater stability to an increase in the hydrogenation probability due to higher current densities. In addition, the higher electron energies lead to an increase in $\sigma$. Recent scanning tunneling microscopy studies of graphene on $\mathrm{SiC}$ have shown that, at low $\mathrm{H}$ coverage, $\mathrm{H}$ monomers and dimers form with monomers having a lower binding energy. ${ }^{12}$ At high $\mathrm{H}$ coverage, large hydrogen clusters form, and nearly complete dehydrogenation is observed after annealing at $T$ $=800{ }^{\circ} \mathrm{C}^{12} \mathrm{We}$ propose that at higher biases, larger $\mathrm{H}$ clusters form that require a higher $T$ for removal. In Fig. 4, the average value of $I_{D} / I_{G}$ at RT over all biases for MLG, BLG, and TLG is $2.8 \pm 0.5,2.0 \pm 0.5$, and $1.8 \pm 0.2$, respectively. The lower values for BLG and TLG are attributed to the additional $\mathrm{C}$ layers in these materials.

In conclusion, we have shown that hydrogenation of MLG, BLG, and TLG using $\mathrm{H}_{2}$ plasma results from electron irradiation of $\mathrm{H}_{2} \mathrm{O}$ adsorbates. The temperature stability of the hydrogenation significantly increases at sample biases $>60 \mathrm{~V}$. Irradiation of adsorbates may provide a useful technique for modifying these materials.

We thank Joshua Wahrmund for useful discussions. This work was supported by the Faculty Research Grant program and Center for Advanced Research and Technology at the University of North Texas. The Verbeck group acknowledges support for the plasma work by the AFOSR YIP-08-141 research grant.

${ }^{1}$ K. S. Novoselov, A. K. Geim, S. V. Morosov, D. Jiang, M. L. Katsnelson, I. V. Grigorieva, S. V. Dubonos, and A. A. Firsov, Nature (London) 438, 197 (2005).

${ }^{2}$ D. C. Elias, R. R. Nair, T. M. G. Mohiuddin, S. V. Morozov, P. Blake, M. P. Halsall, A. C. Ferrari, D. W. Boukhvalvov, M. I. Katsnelson, A. K. Geim, and K. S. Novoselov, Science 323, 610 (2009).

${ }^{3}$ S. Ryu, M. Y. Han, J. Maultzsch, T. F. Heinz, P. Kim, M. L. Steigerwald, and L. E. Brus, Nano Lett. 8, 4597 (2008).

${ }^{4}$ Z. Luo, T. Yu, K. Kim, Z. Ni, Y. You, S. Lim, Z. Shen, S. Wang, and J. Lin, ACS Nano 3, 1781 (2009).

${ }^{5}$ J. O. Sofo, A. S. Chaudhari, and G. D. Barber, Phys. Rev. B 75, 153401 (2007).

${ }^{6}$ F. Schedin, A. K. Geim, S. V. Morosov, E. W. Hill, P. Blake, and M. I. Katsnelson, Nature Mater. 6, 652 (2007).

${ }^{7}$ See supplementary material at http://dx.doi.org/10.1063/1.3524517 for details on sample preparation and plasma apparatus.

${ }^{8}$ L. Liu, S. Ryu, M. R. Tomasik, E. Stolyarova, N. Jung, M. S. Hybertsen, M. L. Steigerwald, L. E. Brus, and G. W. Flynn, Nano Lett. 8, 1965 (2008).

${ }^{9}$ Y. Itikawa and N. Mason, J. Phys. Chem. Ref. Data 34, 1 (2005).

${ }^{10}$ A. L. F. de Barros, J. Lecointre, H. Luna, M. B. Sha, and E. C. Montenegro, Phys. Rev. A 80, 012716 (2009).

${ }^{11}$ M. Xu, D. Fujita, and N. Hanagata, Nanotechnology 21, 265705 (2010).

${ }^{12}$ R. Balog, B. Jorgensen, J. Wells, E. Laegsgaard, P. Hofmann, F. Besenbacher, and L. Hornekaer, J. Am. Chem. Soc. 131, 8744 (2009). 